\title{
Lewy body dementia in frailty, a call for a geriatrician
}

Keywords: dementia, frailty, geriatric medicine, lewy body, parkinson disease

\section{Introduction}

We present the case of a 70-year-old man who consulted to outpatient care due to "forgetfulness" referred by his daughter. In his relevant background, there is a previous diagnosis of Parkinson's disease, mayor depression, chronic hypertension and primary hypothyroidism. Five years ago, he debuted with gait disturbances, instability and short steps associated to upper limb tremor and hypophonia for which he was diagnosed with Parkinson's disease (PD) and was started on levodopa/carbidopa. At the same time, he presented memory loss of recent events, placement of objects and appointments and frequent anomic blockades without paraphasias, neologisms or deficits in confrontation naming. Three years ago, he started presenting marked irritability, aggressive behavior, paranoid ideas and visual hallucinations for which he was hospitalized in several opportunities. Insomnia, constipation, nycturia and frequent falls has been present since the beginning, worsening with time.

To the physical exam, we found facial hypomimia, hypophonia, and hypoacusia. He had bradykinesia, impaired and insecure gait with short steps and slouched posture, with his trunk bent forward, absent arm swing and decomposition of quality of turning. Increased muscle tone with symmetrical cog wheel rigidity in all four extremities were also noted, but reflexes were normal. He also presented resting tremor with wrist flexion-extension that interfered with writing. He was disoriented in time, apathic and hypoprosexic.

A comprehensive geriatric assessment (CGA) was performed: Functional (Barthel index-35/100, Lawton-scale0/8), mental (Yesavage 8/15, Montreal Cognitive Assessment10/30 (3), Minimental17/30), Nutritional (Mini-Nutritional-Assessment 21/30) (5), social (appropriate formal support, pensioned, institutionalized), frailty index (Possible conditions: 30, Present conditions:15. Frailty index:30/15=0.5). It elucidates a frail ${ }^{1}$ patient with severe dependency for daily life activities.,3 The neuropsychological evaluation (Figure 1) elucidated a constitutional apraxia and a dissociation in the memory curve (encoding was not affected but recall showed significant deficits). Adding these findings to the functionality level previously described indicate a mayor neurocognitive disorder with corticosubcortical elements in a moderate to severe staging.

This patient has memory complaints and shows a clear Parkinsonism with impairment in executive functions and visuospatial capacities with visual hallucinations which is highly suggestive of dementia by Lewy bodies (DLB). ${ }^{4}$ However, he is also affected by non-motor symptoms and comorbidities such as primary hypothyroidism, recurrent falls, chronic controlled hypertension (AHT), hypoacusia, malnutrition risk, constipation, apathy, insomnia and severe functional impairment.

When the behavioral symptoms started, his doctors prescribed antipsychotics. Hence his motor symptoms worsened, possibly due to marked neuroleptic susceptibility in DLB patients. ${ }^{4}$ As a follow-up, he continued to consult with neurologists that increased levodopa dosage and started on dopamine agonists and monoamine oxidase inhibitors
Volume 2 Issue 2 - 2017

\author{
Miguel Germán Borda, ${ }^{1,2,3}$ María Zuluaga, ${ }^{\prime}$ \\ Elkin Garcia-Cifuentes, ${ }^{1,3}$ Diego Andrés \\ Chavarro-Carvajal, ${ }^{1,2,3}$ Carlos Alberto Cano ${ }^{1,2}$ \\ 'Semillero de Neurociencias y Envejecimiento, Pontificia \\ Universidad Javeriana, Colombia \\ ${ }^{2}$ Unidad de Geriatría, Hospital Universitario San Ignacio Bogotá \\ DC, Colombia \\ ${ }^{3}$ Instituto de Envejecimiento, Pontificia Universidad Javeriana, \\ Colombia
}

Correspondence: Miguel Germán Borda, Senior Medicine, Medicina del Adulto Mayor y Clínica de Memoria, Pontificia Universidad Javeriana, Colombia, Tel 0057304 5451043, Emailmmborda@gmail.com

Received: June 17, 2017| Published: September 12, 2017

B (MAOI-B), which further deteriorated even more his behavioral issues. This, in turn spun into a cycle that did not bring benefits for the patient and ended up in ineffective treatment and ill managed patient and professional time. Important discrimination techniques to differentiate DLB from PD associated dementia are crucial and include identifying that PD patient's generally present dementia 10 years after onset of motor symptoms and usually have positive levodopa responsivity. Consequently DLB should be diagnosed if dementia occurs before (one year rule) or concurrently with the motor symptomatology. ${ }^{2}$

A progressive decline in levodopa dosage was necessary per tolerance and patient response. Management plan was to continue follow-up with neurology, psychiatry, clinical nutrition and geriatrics, being the Geriatrician the team leader because we were facing a fragile patient (Figure 1). Furthermore, memantine was suspended and rivastigmine patches $9 \mathrm{mg} / 5 \mathrm{~cm} 2$ per day were started with monthly increments up to $27 \mathrm{mg} / 15 \mathrm{~cm}^{2}$. Lactulose $10 \mathrm{~g}$ in the morning was also prescribed along with physical, occupational and language therapy and psychoeducation for family members. Antipsychotic and benzodiazepine use was advised against, but if necessary quetiapine was the indicated treatment. Lastly, legal protection measures were taken and permanent accompaniment was advised.

Henceforward, clinicians should have a high index suspicion and screen all dementia patients for DBL with the criteria previously mentioned which have shown high sensitivity and specificity (depending on clinician experience being almost 90\% in experienced clinicians and $55 \%$ on the most inexperienced ones) having particular attention to the elderly presentation mentioned in this case. ${ }^{4}$ It is crucial to consider not only the main mental diagnosis but all other aspects of the patient including clinical comorbidities, pharmacological peculiarities and interactions in elderly patients, non-motor symptoms, nutritional profile, falls and social support as these can greatly alter the progression, management options, adherence and quality of life. Therefore, clinicians should always treat persons and not just isolated symptoms. 


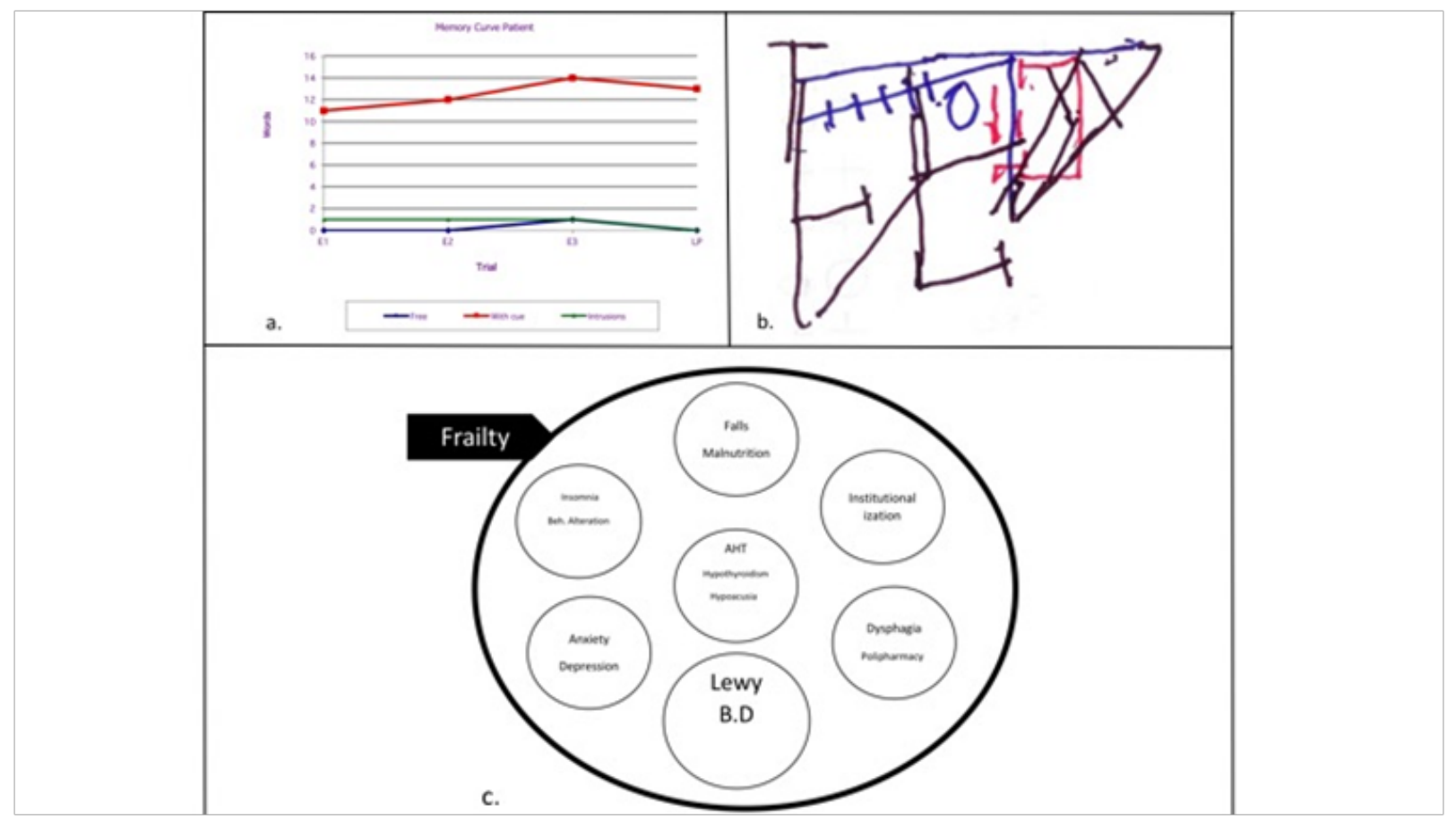

Figure I(A) Memory assessment tool: the explicit verbal learning test shows adequate storage volume of new information and growing retention curve maintained long term. However, he has severe difficulty in information recall (cero free evocation) and must rely on semantic clues to access data.

Figure I (B) Rey-Osterrieth complex figure test, part of the neuropsychological evaluation. Results demonstrate a franc constitutional apraxia and inability to reproduce models. This was also appreciated in the copying of simple figures.

Figure I(C) Scheme showing that the diagnosis of DLB does not always come alone in elderly patients. It is common that it comes with several conditions which configure a frail person.

\section{Acknowledgements}

None.

\section{Conflicts of interest}

Authors declare there is no conflict of interest in composing this manuscript.

\section{References}

1. Tabue TM, Kelaiditi E, Demougeot L, et al. Frailty Index and Mortality in Nursing Home Residents in France: Results from the INCUR Study. $J$ Am Med Dir Assoc. 2015;16(7):603-606.
2. Yesavage JA, Brink TL, Rose TL, et al. Development and validation of a geriatric depression screening scale: a preliminary report. $J$ Psychiatr Res. 1982;17(1):37-49.

3. Hoops S, Nazem S, Siderowf AD, et al. Validity of the MoCA and MMSE in the detection of MCI and dementia in Parkinson disease. Neurology. 2009;73(21):1738-1745.

4. McKeith I, Fairbairn A, Perry R, et al. Neuroleptic sensitivity in patients with senile dementia of Lewy body type. BMJ. 1992;305(6855):673-678.

5. Guigoz Y, Vellas B, Garry PJ. Assessing the nutritional status of the elderly: the Mini Nutritional Assessment as part of the geriatric evaluation. Nutr Rev. 1996;54:S59- S65. 